Original Research Article

\title{
A comparative evaluation of diclofenac and tramadol as post-operative analgesics along with causality and severity assessment of ADRs
}

\author{
Iram Shaifali ${ }^{1}$, Suruchi Prakash ${ }^{1}$, Shalini Chandra ${ }^{1 *}$, Jagdamba Saran ${ }^{2}$
}

\begin{abstract}
${ }^{1}$ Department of Pharmacology,
${ }^{2}$ Department of Surgery,

Rohilkhand Medical College,

Bareilly, Uttar Pradesh, India
\end{abstract}

Received: 29 January 2019

Accepted: 06 March 2019

*Correspondence to:

Dr. Shalini Chandra,

Email: pharmapublications@ rediffmail.com

Copyright: (C) the author(s), publisher and licensee Medip Academy. This is an openaccess article distributed under the terms of the Creative Commons Attribution NonCommercial License, which permits unrestricted noncommercial use, distribution, and reproduction in any medium, provided the original work is properly cited.

\begin{abstract}
Background: Diclofenac and Tramadol are well established analgesics for postoperative pain management, yet some adverse effects are associated with their use which govern their tolerability. The objective of the study was to evaluate the comparative efficacy of the two drugs and to assess the causality and severity of documented Adverse Drug Reactions (ADRs).

Methods: An open labelled, prospective, interventional, simple randomized clinical study to compare efficacy and safety of diclofenac and tramadol was conducted by the Department of Pharmacology in collaboration with the Department of Surgery. Post-operative pain intensity was measured on Visual Analogue Scale (VAS). Causality and severity assessment of the recorded ADRs was done using WHO-UMC scale and modified Hartwig and Seigel Scale respectively.

Results: A total of 211 patients underwent different surgeries. The most common surgery performed was mesh hernioplasty 78 (36.96\%). VAS score was used as data to determine the analgesic efficacy of two drugs. Wilcoxon Signed Rank test showed significant reduction in pain on all days for each group individually while Mann Whitney U test compared both the groups and revealed that both the drugs i.e. diclofenac and tramadol were equally efficacious in reducing post-operative pain. Causality assessment showed that all the documented ADRs fall in POSSIBLE category while severity assessment revealed that all the ADRs were MILD in nature.

Conclusions: Diclofenac and tramadol proved to be equi-effective in reducing post-operative pain. The study also emphasized that active surveillance of ADRs can lead to timely intervention and provide maximum benefit to the patient.
\end{abstract}

Keywords: ADRs, Causality and severity assessment, Diclofenac, Tramadol, VAS-score

\section{INTRODUCTION}

International association for the study of pain defines it as "An unpleasant sensory and emotional experience associated with actual and potential tissue damage."1-5 Pain is an inevitable part of any surgical procedure. Effective post-operative pain management is crucial for speedy recovery, prompt mobility and prevention of postoperative complications. ${ }^{6,7}$ In this study, we studied pain due to tissue injury following surgery. Tissue injury leads to increase in prostaglandins synthesis which is the cause of pain. Pain is a subjective perception, however, to assess pain various methods used are - visual analogue scale, numeric rating scale, Mac Gill pain questionnaire and Short form Mac Gill pain questionnaire etc.

Just as every coin has two sides similarly every drug can also produce therapeutic benefit and adverse effects. Hence before selecting any drug for any particular indication we should always assess its risk-benefit ratio also. With this idea in mind, we conducted this study to generate evidence-based data for choosing the most effective post-operative analgesic- either Diclofenac or Tramadol. Besides this, we also did the causality and severity assessment of adverse effects produced by these drugs. 


\section{METHODS}

It was conducted as an open labelled, prospective, interventional, simple randomized clinical study to compare efficacy and safety of Diclofenac and Tramadol by the Department of Pharmacology in collaboration with the Department of Surgery, Rohilkhand Medical College and Hospital, Bareilly from $1^{\text {st }}$ October $2016-30^{\text {th }}$ September 2017. Institutional Ethical Committee clearance and The Registration from Clinical Trial Registry India (CTRI) were sought before commencing the study. The research protocol was explained to the patients who were planned for elective surgeries. Those who fulfilled the inclusion criteria were enrolled and written informed consent was taken from them.

\section{Inclusion criteria}

Patients of both genders, above 18 - 65 years of age and having normal renal and hepatic function tests.

\section{Exclusion criteria}

- History of allergy/ hypersensitivity to diclofenac or tramadol

- History of seizures/gastric ulcers/congestive heart failure

- Patients on antidepressants

- Pregnant and lactating females

\section{Monitoring and follow up}

A total of 211 patients constituted the sample size. All these patients included in the research received uniform pre-operative and intra-operative medications. The selected patients were randomly divided into 2 equal groups. The first group i.e. 'D'- group was prescribed Diclofenac whereas the second group i.e. ' $\mathrm{T}$ '- group was prescribed Tramadol for post-operative pain. Equianalgesic doses of diclofenac and tramadol were used in the respective groups. D group was given Inj. diclonac 75 $\mathrm{mg}$ (Lupin) in $100 \mathrm{ml}$ of normal saline twice a day while the $\mathrm{T}$ group was given Injection contramal $100 \mathrm{mg}$ (Abott) in $100 \mathrm{ml}$ of normal saline B.D. The parenteral route was used for day 1 and day 2 after surgery. From the 3rd day onwards, all the patients were shifted to the oral drugs. Dgroup received oral diclofenac $75 \mathrm{mg}$ B.D (Tablet diclonac $75 \mathrm{mg}$-Lupin) while the T-group received $100 \mathrm{mg}$ tramadol B.D (Tablet contramol $100 \mathrm{mg}$-Abott). All the patients were followed till 6th post-operative day and on day- 7, all the patients were discharged.

The pain intensity was measured using Visual Analogue Scale. Visual analogue scale was first described by Haynes and Patterson in 1921. It is a $10 \mathrm{~cm}$ or $100 \mathrm{~mm}$ horizontal line where left side has 0 marking while right side has 100 $\mathrm{mm} / 10 \mathrm{~cm}$ markings. The zero marking indicates no pain while $10 \mathrm{~cm} / 100 \mathrm{~mm}$ indicates extreme excruciating pain/intolerable pain. ${ }^{8,9}$
The grading of score is as follows ${ }^{10}$

- No pain 0-4 mm

- Mild pain 5-44 mm

- Moderate pain 45-74 mm

- Severe pain $>75 \mathrm{~mm}$

Patients were explained the use of VAS a day before surgery. The VAS takes 1 minute to complete. ${ }^{11,12}$ Pain was assessed daily at the same time of the day, using VAS score, till 6th post-operative day by separate investigators who were blinded to the analgesic used. Patients who required an additional dose of analgesia, in whom pain did not subside with the regular protocol dose and also those patients who developed complications were excluded from the study.

\section{Safety assessment}

The WHO definition of an ADR was adapted. Each reported ADR was assessed for its casualty by using WHO-UMC causality assessment scale. (Table-I)Then causality grading is done as certain, probable/likely, possible, doubtful, unlikely. ${ }^{13}$

\section{Severity assessment}

Evaluations of severity of adverse drug reaction were assessed using Modified Hartwig and Siegel Scale which classifies ADRs into mild, moderate and severe.

\section{Statistical analysis}

Data processing was done by using Statistical Package for the Social Science, Version 23 software which is developed by IBM. Both descriptive and inferential data analyses were done using Chi-square test, Wilcoxsonsigned rank test and Mann Whitney-U Test. The results were displayed with the help of tables and graphs.

\section{RESULTS}

Out of total of 211 patients, $173(82 \%)$ were males and 38 were females $(18 \%)$. Male female ratio in group $\mathrm{D}$ and group $\mathrm{T}$ were 4.83 and 4.3 respectively. $\left(\mathrm{X}^{2}=0.106, \mathrm{p}=\right.$ 0.744 ). The mean age groups in $\mathrm{D}$ and $\mathrm{T}$ group were 40.83 and 38.83 respectively. In group $\mathrm{D}$ and $\mathrm{T}$, urban to rural ratio was 0.45 and 0.3 respectively. Hence both groups were statistically comparable with regards to demographic distribution also. $\left(\mathrm{X}^{2}=0.154, \mathrm{p}=0.695\right)$ (Table 1).

A total of 211 patients underwent different surgeries. The most common surgery performed was mesh hernioplasty $78(36.96 \%)$ followed by cholecystectomy $66(31.27 \%)$. Chi-square test showed no statistical difference between different types of surgeries performed in the two groups was observed $(\mathrm{p}=0.821)$ (Figure 1$)$.

Pain assessment was done using VAS. On the day of operation, VAS was not taken as patient under the effect of 
anesthesia or sedation would not be able to mark the point on VAS. From day 1 onwards, VAS-score was taken, and the scale reading was converted to pain grading that is mild, moderate and severe.

Table 1: Demographic profile of the study participants.

\begin{tabular}{|llll|}
\hline Variable & Diclofenac & Tramadol & p value \\
\hline $\begin{array}{l}\text { Mean age } \\
\text { (years) }\end{array}$ & $40 \pm 9.23$ & $38 \pm 9.04$ & 0.691 \\
\hline $\begin{array}{l}\text { Mean weight } \\
(\mathrm{kg})\end{array}$ & $69.21 \pm 7.6$ & $69.42 \pm 9.33$ & 0.862 \\
\hline Male-female & $4.83(87 / 18)$ & $4.3(86 / 20)$ & 0.744 \\
\hline Urban-rural & $0.45(33 / 72)$ & $0.51(36 / 70)$ & 0.695 \\
\hline $\begin{array}{l}\text { Surgical time } \\
\text { (mins) }\end{array}$ & $33.86 \pm 3.68$ & $32.54 \pm 3.75$ & 0.120 \\
\hline
\end{tabular}

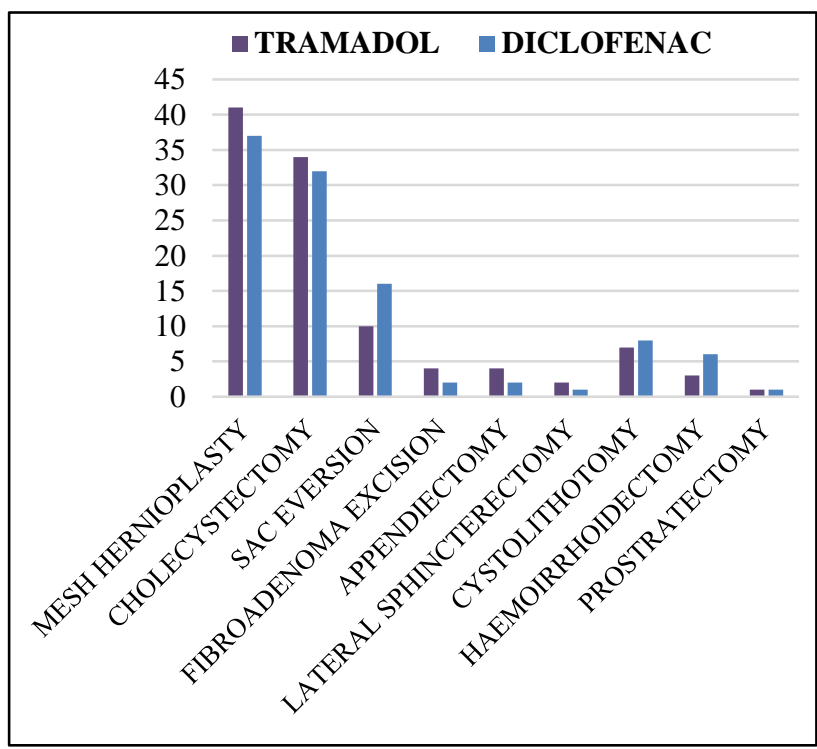

Figure 1: Types of surgeries performed in both the groups.

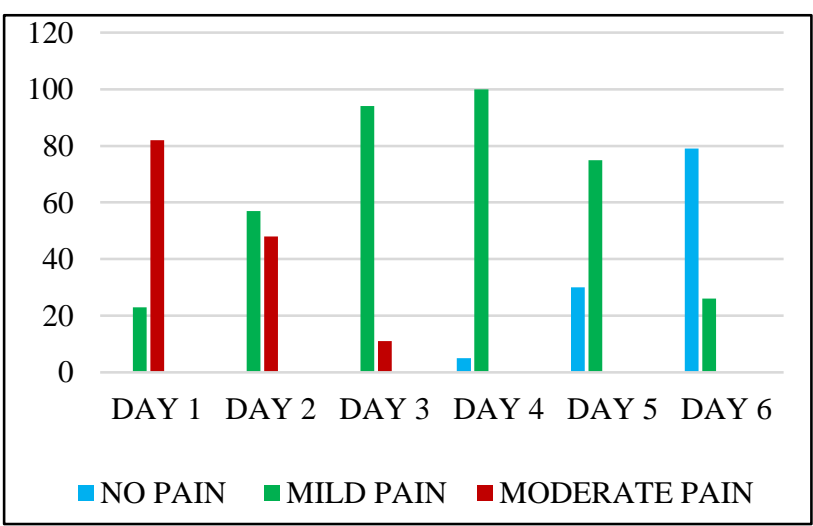

Figure 2: Pain reduction in diclofenac group.

Pain assessment of day-1 was taken as baseline. On day 1 , 82 and 87 patients had moderate pain while 23 and 19 patients had mild pain in group $\mathrm{D}$ and group $\mathrm{T}$ respectively.
On day 2, 48 and 53 patients had moderate pain while 57 and 53 patients had mild pain in $\mathrm{D}$ and $\mathrm{T}$ groups respectively. There was decrease in number of patients with moderate pain while increase in number of patients with mild pain.

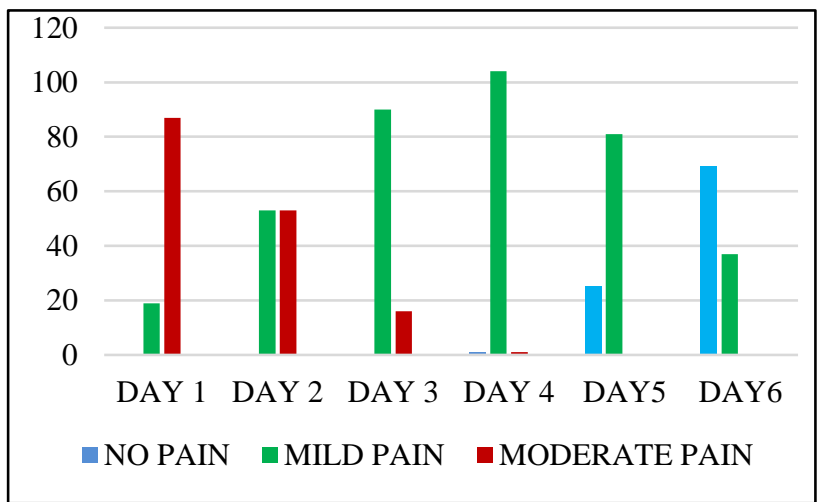

Figure 3: Pain reduction in tramadol group.

Table 2: Wilcoxan Signed Rank test showing reduction in pain in diclofenac group.

\begin{tabular}{|c|c|c|c|}
\hline \multicolumn{4}{|l|}{ Diclofenac group } \\
\hline $\begin{array}{l}\text { Baseline (day 1) } \\
\text { Mean } \pm \text { S.D }\end{array}$ & $\begin{array}{l}\text { Follow-up } \\
\text { Mean } \pm \text { S.D }\end{array}$ & 'z' value & 'p' value \\
\hline $2.78 \pm 0.415$ & $\begin{array}{l}2.45 \pm 0.505 \\
\text { (day 2) }\end{array}$ & -5.376 & 0.001 \\
\hline $2.78 \pm 0.415$ & $\begin{array}{l}2.104 \pm 0.307 \\
\text { (day 3) }\end{array}$ & -8.426 & 0.001 \\
\hline $2.78 \pm 0.415$ & $\begin{array}{l}1.95 \pm 0.214 \\
\text { (day 4) }\end{array}$ & -9.327 & 0.001 \\
\hline $2.78 \pm 0.415$ & $\begin{array}{l}1.714 \pm 0.454 \\
(\text { day } 5)\end{array}$ & -9.273 & 0.001 \\
\hline $2.78 \pm 0.415$ & $\begin{array}{l}1.247 \pm 0.434 \\
\text { (day 6) }\end{array}$ & -9.147 & 0.001 \\
\hline
\end{tabular}

Table 3: Wilcoxon Sign Rank test showing reduction in pain in tramadol group.

\begin{tabular}{|llll|}
\hline $\begin{array}{l}\text { Baseline (day 1) } \\
\text { Mean } \pm \text { S.D }\end{array}$ & Follow-up & ' $z$ ' value & 'p' value \\
\hline $2.82 \pm 0.385$ & $\begin{array}{l}2.50 \pm 0.502 \\
\text { (day 2) }\end{array}$ & -5.83 & 0.001 \\
\hline $2.82 \pm 0.385$ & $\begin{array}{l}2.15 \pm 0.359 \\
\text { (day 3) }\end{array}$ & -8.426 & 0.001 \\
\hline $2.82 \pm 0.385$ & $\begin{array}{l}2.00 \pm 0.138 \\
\text { (day 4) }\end{array}$ & -9.327 & 0.001 \\
\hline $2.82 \pm 0.385$ & $\begin{array}{l}1.70 \pm 0.426 \\
\text { (day 5) }\end{array}$ & -8.881 & 0.001 \\
\hline $2.82 \pm 0.385$ & $\begin{array}{l}1.35 \pm 0.481 \\
\text { (day 6) }\end{array}$ & -9.139 & 0.001 \\
\hline
\end{tabular}

p $>0.05$ - Not Significant; $p<0.05$ - Significant; $p<0.001$ - Highly Significant 
On day 3, 11 and 16 patients had moderate pain while 94 and 90 patients had mild pain in $\mathrm{D}$ and $\mathrm{T}$ groups respectively.

On day 4, 100 and 104 patients had mild pain while 5 and 1 patient had no pain in $\mathrm{D}$ and $\mathrm{T}$ groups respectively.

On day 5, 75 and 81 patients had mild pain while 30 and 25 patients had no pain in $\mathrm{D}$ and $\mathrm{T}$ groups respectively.

On day 6, only 26 and 37 patients had mild pain while 79 and 69 had no pain in D and T groups respectively. It was observed that there was reduction of pain from moderate to mild pain and even to no pain in both the groups. Pain score was taken till Day 6 only as they were discharged on the $7^{\text {th }}$ day while some preferred to go home on the evening of $6^{\text {th }}$ day (Figure 2 and 3).

Wilcoxon Signed Rank test showed that there was significant reduction in pain on all days for each group separately (Table 2 and 3). Mann Whitney U test compared both the groups and revealed that both the drugs i.e. diclofenac and tramadol were equally efficacious in reducing post-operative pain (Table 4 ).

Table 4: Mann-Whitney test showing comparative pain reduction in both the groups.

\begin{tabular}{|lllll|}
\hline $\begin{array}{l}\text { Follow- } \\
\text { up } \\
\text { visits }\end{array}$ & $\begin{array}{l}\text { Tramadol } \\
\text { (Mean } \\
\text { rank) }\end{array}$ & $\begin{array}{l}\text { Diclofenac } \\
\text { (Mean } \\
\text { rank) }\end{array}$ & $\begin{array}{l}\text { ' } z \text { ' } \\
\text { value }\end{array}$ & $\begin{array}{l}\text { 'p' } \\
\text { value }\end{array}$ \\
\hline Day 1 & 108.09 & 103.89 & -0.722 & 0.470 \\
\hline Day 2 & 108.25 & 103.73 & -0.622 & 0.534 \\
\hline Day 3 & 108.42 & 103.55 & -1.002 & 0.316 \\
\hline Day 4 & 108.48 & 103.50 & -1.908 & 0.056 \\
\hline Day 5 & 108.62 & 103.36 & -0.823 & 0.410 \\
\hline
\end{tabular}

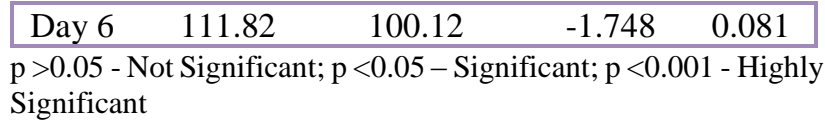

Significant

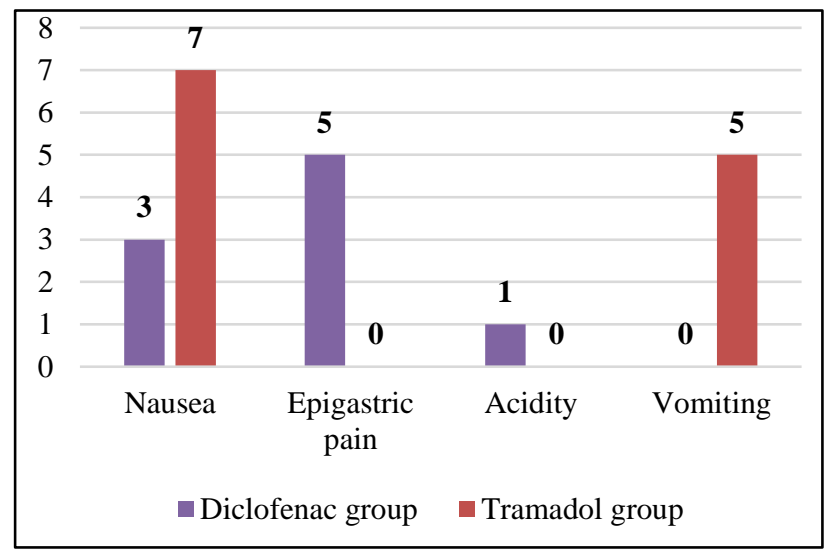

Figure 4: Number of adverse effects in both groups.

Present study also depicted that both diclofenac and tramadol were safe drugs. Among 211 patients, 21 Adverse Drug Reactions were reported (Figure 4). A total of $9.95 \%$ of the patients presented with side-effects, out of which diclofenac group accounted for $8.57 \%$ and $11.3 \%$ adverse effects were reported by tramadol group.

A total of, 9 adverse effects $(8.56 \%)$ were reported in the diclofenac group. Nausea was reported 3 times after drug administration within 2 hours. After the causality assessment, we found that nausea had a 'POSSIBLE' association with drug administration. All the three reports of nausea were of 'Mild Grade' according to Hartwig Siegel's Scale. In two patients nausea subsided on its own while in one case injection ondansetron was given intramuscularly.

Table 5: WHO-UMC causality assessment scale of ADRs of both groups.

\begin{tabular}{|lll|llllll|}
\hline ADRs & Certain & & Probable & \multicolumn{2}{c|}{ Possible } & & Unlikely \\
& Diclofenac & Tramadol & Diclofenac & Tramadol & Diclofenac & Tramadol & Diclofenac & Tramadol \\
\hline Nausea & - & - & - & - & $3(2.85 \%)$ & $7(6.6 \%)$ & - & - \\
\hline Vomiting & - & - & - & - & - & $5(4.71 \%)$ & - & - \\
\hline $\begin{array}{l}\text { Epigastric } \\
\text { pain }\end{array}$ & - & - & - & - & $5(4.76 \%)$ & - & - & - \\
\hline Acidity & - & - & - & - & $1(0.95 \%)$ & - & - & - \\
\hline
\end{tabular}

Table 6: Hartwig Siegel severity assessment of ADRs of both groups.

\begin{tabular}{|lllllll|}
\hline ADRs & Mild & & Moderate & & Severe \\
& Diclofenac & Tramadol & Diclofenac & Tramadol & Diclofenac & Tramadol \\
\hline Nausea & 3 & 7 & - & - & - & - \\
\hline Vomiting & - & 5 & - & - & - & - \\
\hline Epigastric pain & 5 & - & - & - & - & - \\
\hline Acidity & 1 & - & - & - & - & - \\
\hline
\end{tabular}


Among the reports of epigastric pain with oral diclofenac, 5 patients complained of epigastric pain. This complain was seen when the patients were shifted from parenteral to oral formulation. This was classified as 'POSSIBLE' causality association. The severity of epigastric pain was found to be of 'Mild Grade'.

Only one patient complained of acidity, on day 4 after surgery. The possible reason for the event could be that patient skipped the meal and took the drug on empty stomach. Causality assessment classified it as a 'POSSIBLE' association. It was found to fall in 'Mild Grade' based on Hartwig Siegel's scale.

From 106 patients in tramadol group, 12 (11.3\%) adverse events were reported. Nausea was seen in 7 cases while 5 cases complained of vomiting. Nausea was the most common complaint in the tramadol group, especially when parenteral route was used that is before shifting to oral medications. The causality association of nausea was 'POSSIBLE' on all the occasions. Intramuscular injection of ondansetron was given to 5 patients while 2 patients refused the injections as nausea subsided on its own. On Hartwig and Siegel scale of severity assessment, nausea was categorized as 'Mild Grade' on all occasions.

Vomiting was seen in 5 patients in tramadol group. Causality assessment showed it to be a 'POSSIBLE' association (Table 5). On Hartwig Siegel's scale (Table 6) the event was of 'Mild Grade'.

\section{DISCUSSION}

Pain is the part and parcel of any surgical procedure and its effective control plays a crucial role in the faster recovery and also improved patient satisfaction. Pain is one of the most common symptoms for which medical advice is seek. Authors conducted the study to compare the efficacy and tolerability of diclofenac and tramadol for the postoperative pain management in patients undergoing major elective surgeries in the surgery department.

\section{Demography profile}

Pain perception is an important component of pain assessment and males and females have different perception. Females have a lower threshold of pain and hence perceive more pain while males have a higher threshold of pain and hence perceive less pain. On analyzing the demographic details, we found that in our study the male-female ratio (D-4.83 and T-4.3) was comparable in both the groups. Other studies have also stated almost similar male-female ratio.14The average age of participants was $39.47 \pm 9.14$ years. About $36.49 \%$ of pat322 qients were in the range of $35-45$ years in the study population. Our findings regarding mean age in groups are in line with other researchers. ${ }^{15}$ Though in our study, age showed no relevance with pain but some studies have depicted that as age increases pain also increases while other studies suggests that with advancing age the pain decreases as degeneration of nerves occur. ${ }^{16-17}$ About $67 \%$ of the study population belonged to the rural background while $33 \%$ of the population belonged to the urban area. The locality distribution of our study population is in concordance with other authors15.The present study includes various surgeries e.g. mesh hernioplasty, sac eversion, excision of fibroadenoma, cholecystectomy to name a few, which were done by the surgery department. Other studies have also included similar surgeries. ${ }^{18}$

\section{Comparative efficacy of diclofenac and tramadol as analgesics}

Although, both the drugs individually produced statistically significant $(\mathrm{p}=0.001)$ reduction in the post operative pain at each follow-up but there was no statistically significant difference $(p>0.05)$ in the reduction of pain intensity when we compared the efficacy of two drugs with each other at each follow-up. Our study was in favor of some studies while few other studies contradict it.

The present study results were that both drugs were equally effective in reducing postoperative pain. Similar findings were seen in the study carried out by Panse et al, who compared diclofenac rectal suppository with that of tramadol rectal suppository. ${ }^{19}$ They recorded VAS-score at regular intervals of $1,2,4,6,8,10$ and 12 hours. It was observed that both the drugs were equally effective in reducing pain though the side effects of nausea and vomiting was much less with rectal suppository.

Majeed et al, also had similar findings that both diclofenac (100mg OD) and tramadol (200mg OD) are equally effective in reducing pain in patients with osteoarthritis of knee joint. ${ }^{20}$ The results of study conducted by Kamtane et al, on post-operative patients of surgery, obstetrics, orthopedic and urologic departments are also in concordance with our study findings. ${ }^{15}$ Similarly findings of Courtney et al, are in line with our results who also found no significant difference between the analgesic efficacy of diclofenac and tramadol in patients undergoing tonsillectomy. ${ }^{21}$

On the other hand, present study findings were contradictory to some authors in the field obtained. Shukla et al, documented diclofenac as a better drug than tramadol in reducing post-operative pain in patients undergoing hydrocele and inguinal hernia surgery. ${ }^{22}$ Similarly Ujjaini et al, Salameh et al, and Pandit et al, proved better analgesic efficacy of diclofenac. ${ }^{18,23,24}$ SP Sinha et al, carried out a study among patients undergoing laparoscopic cholecystectomy. ${ }^{14}$ VAS was taken after 4, 12, 20 and 24 hours after surgery for pain assessment. They concluded that tramadol was more effective in reducing pain than diclofenac.

\section{Adverse drug reactions}

Then, tolerability profile of diclofenac and tramadol was assessed. In 24 patients adverse effects were seen in overall 
study population. The adverse effects frequently observed in diclofenac group were epigastric pain $(4.76 \%)$ followed by nausea $(2.85 \%)$ and acidity $(0.95 \%)$. In tramadol group, the most common side effect observed were nausea $(6.6 \%)$ followed by vomiting $(4.71 \%)$. Similar pattern of ADR occurrence due to Diclofenac and Tramadol was reported by Hussain et al, in post- hysterectomy patients and by Paivi Laurilla Nee, in post-operative patients of joint surgery. ${ }^{25,26}$

Causality assessment was done using WHO-UMC Causality assessment scale. All the adverse effects observed were of POSSIBLE category as the events occurred in the period of drug administration. The possible explanation for the side effect like nausea and vomiting was that Diclofenac degrades the defensive/protective gastro-intestinal mucosal barrier by inhibiting the prostaglandin synthesis (PGE2) while Tramadol causes stimulation of the $\mu$ receptors present in the chemoreceptor trigger zone. The same reason is self- explanatory for the side effects like acidity and epigastric pain.

The ADRs produced by diclofenac as well as tramadol were graded to be of Mild category according to modified Hartwig and Siegel scale. Both the groups were given injection ondansetron and injection pantoprazole to overcome nausea, vomiting and acidity respectively. Present results are in agreement with those of Sidhu HS et al, who conducted a study on evaluation of ADR pattern by NSAIDs in orthopedics OPD and reported that maximum number of ADRs were from GIT system. ${ }^{27}$ Their study results also classified maximum ADRs as Probable according to WHO causality and most of the reactions were of mild to moderate severity on Hartwig Siegel Scale.

\section{CONCLUSION}

Post-operative pain has really been a matter of concern for both patients as well as treating surgeons since decades. The postoperative pain management has undergone major development with the evolution of newer drugs. The results of this comparative, prospective study revealed that both diclofenac and tramadol are equi-effective in reducing post-operative pain. Hence, it can be said that diclofenac $75 \mathrm{mg}$ B.D is equally effective as tramadol $100 \mathrm{mg}$ B.D. in reducing post-operative pain. As far as tolerability of both the drugs is concerned the pattern of ADRs was almost similar in both the groups. Moreover, causality and severity assessment by standard scales showed no significant difference between the two groups, though incidence of nausea and vomiting were more in Tramadol group than in Diclofenac group. This study has paved the way to carry out active surveillance and building a database for ADRs due to diclofenac and tramadol by conducting studies on larger population and for a longer time-frame.

\section{ACKNOWLEDGEMENTS}

Authors would like to acknowledge the support and cooperation of Dr. Jagdamba Saran, Consultant Surgery
Department and the study participants without whom this study was impossible.

Funding: No funding sources

Conflict of interest: None declared

Ethical approval: The study was approved by the Institutional Ethics Committee of RMCH (REF/2018/03/017965)

\section{REFERENCES}

1. Lee M.C, A Mark. Pain and analgesics. Laurence D R, Bennet P N, Brown MJ.Clinical pharmacology.11th ed. Churchill Livingstone; 2013:278-294.

2. Meissner W, Coluzzi F, Fletcher D, Huygen F, Morlion B, Neugebauer $\mathrm{E}$, et al. Improving the management of post-operative acute pain: priorities for change. Curr Med Res Opinion. 2015;31(11):2131-43.

3. Terminology IP. International Association for the Study of Pain Committee on Taxonomy. Washington DC, IASP, 2014.

4. PAIN C. Pain Management: Classifying, understanding, and treating pain. Hospital Physician. 2002 Jun;23-30.

5. Gupta A, Kaur K, Sharma S, Goyal S, Arora S, Murthy RS. Clinical aspects of acute post-operative pain management \& its assessment. J Adv Pharmaceut Technol Res. 2010;1(2):97-108.

6. Merskey H. Pain terms: a list with definitions and notes on usage. Recommended by the IASP Subcommittee on Taxonomy. Pain. 1979;6:249-52.

7. Shang $A B$, Gan TJ. Optimising postoperative pain management in the ambulatory patient. Drugs. 2003;63(9):855-67.

8. Huskisson EC. Measurement of pain. Lancet. 1974;304(7889):1127-31.

9. Joyce CR, Zutshi DW, Hrubes V, Mason RM. Comparison of fixed interval and visual analogue scales for rating chronic pain. Eur J Clin Pharmacol. 1975;8(6):415-20.

10. Jensen MP, Chen C, Brugger AM. Interpretation of visual analog scale ratings and change scores: a reanalysis of two clinical trials of postoperative pain. J Pain. 2003;4(7):407-14.

11. Downie WW, Leatham PA, Rhind VM, Wright V, Branco JA, Anderson JA. Studies with pain rating scales. Ann the Rheumatic Dis. 1978;37(4):378-81.

12. Burckhardt CS, Jones KD. Adult measures of pain: the McGill Pain Questionnaire (MPQ), Rheumatoid Arthritis Pain Scale (RAPS), Short-Form McGill Pain Questionnaire (SF-MPQ), Verbal Descriptive Scale (VDS), Visual Analog Scale (VAS), and West HavenYale Multidisciplinary Pain Inventory (WHYMPI). Arthritis Care Res: J Am Coll Rheumatol. 2003 Oct 15;49(S5):S96-104.

13. Srinivasan R, Ramya G. Adverse drug reactioncausality assessment. Int $\mathrm{J}$ Res Pharm Chem. 2011;1(3):606-12. 
14. Sinha SP, Sinha S, Sharma SC, Jain S, Hai A. Efficacy of Tramadol V/s Diclofenac in Management of Post Laparoscopic Cholecystectomy Pain. Int J Sci Study. 2013;1(3):89-94.

15. Rajesh A. Safety and efficacy of tramadol compared to diclofenac in relieving postoperative pain. J Evidence Based Med Healthcare. 2015;2(21):310310.

16. Lautenbacher S, Kunz M, Strate P, Nielsen J, ArendtNielsen L. Age effects on pain thresholds, temporal summation and spatial summation of heat and pressure pain. Pain. 2005;115(3):410-8.

17. Rittger H, Rieber J, Breithardt OA, Dücker M, Schmidt M, Abbara S, et al. Influence of age on pain perception in acute myocardial ischemia: A possible cause for delayed treatment in elderly patients. Int $\mathbf{J}$ Cardiol. 2011; 149(1):63-7.

18. Ujjaini M. A comparative study between rectal diclofenac plus paracetamol and injectable tramadol for postoperative pain management in open/laparoscopic appendectomy. J Evidence Based Med Healthcare. 2016;3(43):2114-8.

19. Panse N, Adate KU. Comparison of the analgesic efficacy of tramadol and diclofenac sodium rectal suppository in patients undergoing laparoscopic tubal ligation. Indian J Applied Res. 2018;7(2):30-2.

20. Majeed M, Rasool S, Ahmad A. Incremental costeffectiveness and tolerability of Diclofenac plus Proton pump inhibitor compared to tramadol in the treatment of knee osteoarthritis. Int J Basic Clin Pharmacol. 2018;7(2):252-8.

21. Courtney MJ, Cabraal D. Tramadol vs diclofenac for posttonsillectomy analgesia. Arch Otolaryngol Head Neck Surg. 2001;127(4):385-8.
22. Shukla AK, Srivastav AK. Comparative study of tramadol and diclofenac as analgesic for postoperative pain. Int J Med Res Rev. 2015;3(11):1311-6.

23. Salameh S, Hiller N, Antopolsky M, Ghanem F, Abramovitz Y, Stalnikowics R. Diclofenac versus tramadol in the treatment of renal colic: a prospective, randomized trial. Open Emergency Med J. 2011;4:913.

24. Pandit MK, Godhi S, Lall AB. Preoperative intravenous tramadol versus diclofenac for preventing postoperative pain after third molar surgery: a comparative study. J Maxillofacial Oral Surg. 2011;10(4):306-9.

25. Hussain AM, Khan FA, Sheikh L. Effect of diclofenac suppository on tramadol consumption in posthysterectomy pain. J Coll Physicians Surg Pakistan. 2008;18(9):533-7.

26. PäiviLaurila Née Kostamovaara. Pain relief after joint surgery - A clinical study. 2002:1-63.

27. Sidhu HS, Sadhotra A. Evaluation the pattern of adverse drug reactions by non-steroidal antiinflammatory drugs at the outpatient orthopedics department of a university teaching hospital in north India. Int J Basic Clin Pharmacol 2018;7:1974-80.

Cite this article as: Shaifali I, Prakash S, Chandra S, Saran J. A comparative evaluation of diclofenac and tramadol as post-operative analgesics along with causality and severity assessment of ADRs. Int $\mathbf{J}$ Basic Clin Pharmacol 2019;8:725-31. 